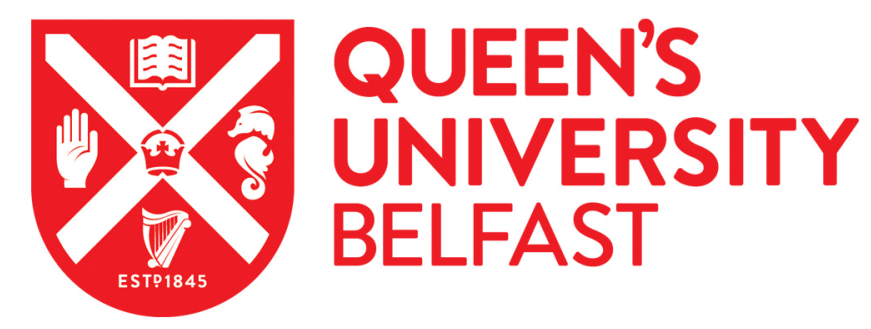

\title{
Experimental Investigation into a Novel Supersaturated Saline Drilling Fluid Available in Anhydrite Formation: A Case study of Missan Oilfields, Iraq
}

Lin, X., Huang, X., You, F-C., Xu, J., Xu, M-B., Gao, J., \& Huang, M. (2020). Experimental Investigation into a Novel Supersaturated Saline Drilling Fluid Available in Anhydrite Formation: A Case study of Missan Oilfields, Iraq. ARABIAN JOURNAL FOR SCIENCE AND ENGINEERING. https://doi.org/10.1007/s13369-020-04911-x

Published in:

ARABIAN JOURNAL FOR SCIENCE AND ENGINEERING

Document Version:

Peer reviewed version

Queen's University Belfast - Research Portal:

Link to publication record in Queen's University Belfast Research Portal

Publisher rights

Copyright King Fahd University of Petroleum \& Minerals 2020.

This work is made available online in accordance with the publisher's policies. Please refer to any applicable terms of use of the publisher.

\section{General rights}

Copyright for the publications made accessible via the Queen's University Belfast Research Portal is retained by the author(s) and / or other copyright owners and it is a condition of accessing these publications that users recognise and abide by the legal requirements associated with these rights.

Take down policy

The Research Portal is Queen's institutional repository that provides access to Queen's research output. Every effort has been made to ensure that content in the Research Portal does not infringe any person's rights, or applicable UK laws. If you discover content in the

Research Portal that you believe breaches copyright or violates any law, please contact openaccess@qub.ac.uk. 


\section{Arabian Journal for Science and Engineering \\ Experimental Investigation into A Novel Supersaturated Saline Drilling Fluid Available in Anhydrite Formation: A Case study of Missan Oilfield, Iraq

\author{
--Manuscript Draft--
}

Manuscript Number:

Full Title:

Article Type:

Section/Category:

Corresponding Author:

Coresponding Author:

Corresponding Author Secondary

Information:

Corresponding Author's Institution:

Corresponding Author's Secondary Institution:

First Author:

Lin $\mathrm{Xu}$

First Author Secondary Information:

Order of Authors:

Lin Xu

Xin Huang

Fu-chang You

Jie $\mathrm{Xu}$

Ming-biao Xu

Mei-lan Huang

Jun Gao
Order of Authors Secondary Information:

Funding Information:

\author{
Zhejiang Province Public Welfare \\ Technology Application Research Project \\ (LGG20E040002) \\ Educational Commission General Project Dr. Lin Xu \\ of Zhejiang Province \\ (Y201840431) \\ Bureau of Science and Technology of Dr. Lin Xu \\ Zhoushan \\ (2019C21006)
}

\section{Abstract:}

The supersaturated saline drilling fluid(SDF) with strong inhibition, as a novel alternative to anhydrite formation drilling, is crucial for the safe and economic drilling operation. In this work, a high performance supersaturated SDF was experimentally formulated in combination to the long anhydrite features of Missan Oilfields. A composite weighting approach involving liquid and solid materials was introduced to reinforce the inhibition of supersaturated SDF. A suite of laboratory tests was conducted to screen the essential viscosifiers and filtrate reducers, and optimize the formula of supersaturated SDF, by means of evaluating the basic rheological and filtration properties. The results showed that univalent salts $\mathrm{NaCl}, \mathrm{KCl}$, and $\mathrm{HCOONa}$ are utilized to formulate the multiple brine phase, and polymeric additives, VIS and SFLO, are selected to improve rheological and filtration properties. The newly developed supersaturated SDF provides the excellent thermal stability, lubricity, as well as inhibition capability, which should be an instructive solution to minimize the hole problems in the anhydrite drilling. 
Dear Reviewers:

We are truly grateful to your critical comments and thoughtful suggestions. Based on these comments and suggestions, we have made careful modifications on the original manuscript and, in particular, the section of "result and discussion" has been partially rewritten. Below you will find our point-by-point responses to the comments (or questions). In the paper, all the modified parts are marked in red.

Response to comment:

Reviewer \#1

Comment 1:

Fig 1:

- Please explain in the caption what do the color codes mean? - Green, yellow, white boxes and the lines.

- Please put all abbreviations in the caption as well even though you have already mentioned them in the paper, e.g. SDF.

- Put space in before ( to be saline drilling fluid (SDF).

- AIM equals to purpose?

- No need all capital if it is not an abbreviation. - Start all word with capital (standardize them)

Response: According to this advice, Fig.1 has been re-presented, and the improper caption has been modified; the color code has been remarked and explained for better understanding; all abbreviations involved in the paper have been elucidated; space has been added;

Comment 2:

Fig 2: Please show the error bars. State in the caption the repeatability. Please put in the caption the full name of each chemicals (abbreviations).

Response: According to this advice, some experiments have been complemented, and error bars have been given in Fig. 2 to state the repeatability. The abbreviations of chemicals are the industrial codes, and they have been introduced in Table 1.

Comment 3:

Fig 3:

- Please show the error bars. State in the caption the repeatability.

- So, black and red refer to left? Put arrow - Write the word legend next to the curve (no need inside a box)

- Legend must use same color as the curve color

Response: According to these advices, Fig. 3 has been reconstructed in the form of bar error. Some improper description has been eliminated. Some detailed information can be found in P14.

Comment 4:

I found many () or [] and you do not use space before ( or [. Please give a space. Response: According to this advice, we checked the paper and the lost space has been added before all () or [].

Comment 5:

Please move all Tables 2-5 into a SUPPLEMENTARY INFORMATION (SI). Show in the paper as figures or bar charts; with known error bar and repeatability.

Response: According to this advice, Tables 2-5 have been provided as a supplementary information together with complementary experiments, and some key information such as rheological and filtrate data has been given in the form of bar chart. The detailed description can be found in the section "results and discussion" in P8-P15.

Comment 6:

Please consider more papers $>7$ from this journal itself. What is the suitability merit to get published here if there is no attachment of references to this journal itself?

Response: Arab. J. Sci. Eng. has involved limited papers on brine drilling fluid system. According to your advice, we have made an effort to cite 6 papers that are contacted with the present work from this journal.

Comment 7:

Please note that the presence of salts may break the polymer or viscosifier chain and results in a lower viscosity; and viscosity increases with increasing polymer concentrations due to the increasing intermolecular entanglement.

Response: According to this advice, we have provided simple description on relation of polymer concentration and intermolecular effect, and cited Hakiki's work. Comment 8:

Please note that the viscosity of fluids is shear-rate dependent. Please declare not only 
the unit mPa.s but also measured at what shear rate? (1/s)

Response: As for rheological property of drilling fluids, the viscosity is always tested with a 6-speed rotator apparatus, which can exhibit relation between viscosity and shear rate. To clarify this point, we have supplied the experimental process in P6. Comment 9:

Regarding comment \#7 and \#8 above, please cite and consider these papers in your references: - Hakiki, F, Maharsi, DA, Marhaendrajana, T. 2015. Surfactant-polymer coreflood simulation and uncertainty analysis derived from laboratory study. Journal of Engineering and Technological Sciences 47 (6), 706-725. DOI:

http://dx.doi.org/10.5614\%2Fj.eng.technol.sci.2015.47.6.9 - Hakiki et al. 2015. Is Epoxy-Based Polymer Suitable for Water Shut-Off Application? SPE-176457-MS. DOI: https://doi.org/10.2118/176457-M

Response: These two papers are instructive to our work, and we have cited them in the section of "screening of viscosifier".

Comment 10:

Make sure all references are mentioned in the paper passage and also provide the DOI link (if any).

Response: all references have been mentioned, and the DOI link (if any) has been provided.

Comment 11:

In the optimization process, please show in new figures the variables you played with. Response: New figures linked with the optimization process were presented in "results and discussion".

Comment 12:

So, which one is the best viscosifier, filtrate reducer, and VIS content? At what concentrations? Could you please create a 3D map optimization? Please give a case study with a given reservoir properties to handle with.

Response: The advice would be helpful to explicitly determine the optimized ingredient, but it will inevitably demand a large quantity of experiments. To meet the requirement on-site, a single-factor experiment is enough and moderate, which is also cost-effective in building appropriate formula. Using the single-factor method, we attained the optimized formula of saturated SDF: fresh water+ 0.25 wt. $\% \mathrm{Na} 2 \mathrm{CO} 3+0.10$ wt. $\%$ $\mathrm{NaOH}+(30$ wt. $\% \mathrm{NaCl}+6$ wt. $\% \mathrm{KCl}+8$ wt. $\% \mathrm{HCOONa})$ mixed-salt water+ 3.0 wt. $\%$ S-FLO + 0.2 wt. $\%$ VIS + barite (1.23 s.g.).

In addition, according to the advice, the title of paper has been modified as "Experimental Investigation into A Novel Supersaturated Saline Drilling Fluid Available in Anhydrite Formation: A Case study of Missan Oilfield, Iraq"

\section{Reviewer \#2}

Comment 1: The experimental part should be supplemented with a description of the experimental procedure used to analyze the dispersion of the drilling fluid, that is, measuring viscosity and fluid loss.

Response: According to this helpful advice, we have complemented experimental procedure.

Comment 2: The article also presents a wide range of different thickeners and filtrate reducing agents. The composition of all types of additives should be described or referred to.

Response: All types of additives are commercially used in petroleum industry, and we presented a description on additive composition in Table 1.

\section{Suggested Reviewers:}

Jihua Cai, Doctor

Professor, China University of Geosciences

caijh@cug.edu.cn

Research interests focus on oilfield chemistry, drilling fluid and technology

Nianyin Li, Doctor

Associated Professor, Southwest Petroleum University

linianyin@swpu.edu.cn

Research interests are focused on oil \& gas exploration and oilfield chemistry

Hanyi Zhong, Doctor

Associated Professor, China University of Petroleum Huadong

zhonghanyi@126.com

his research is focused on oilfield chemistry, design and development of downhole 
working fluid

Xijin Xing, Master

Engineer, China National Offshore Oil Corp

xingxi2@cnooc.com.cn

His research is concentrated on drilling fluids, corrosion and anticorrosion

Chao Ma, Doctor

Professor, Yangtze University

500526@yangtzeu.edu.cn

$\mathrm{He}$ is interested in oilfield chemistry and polymer chemistry. 


\section{Experimental Investigation into A Novel Supersaturated Saline Drilling Fluid Available in Anhydrite Formation: A Case study of Missan Oilfield, Iraq}

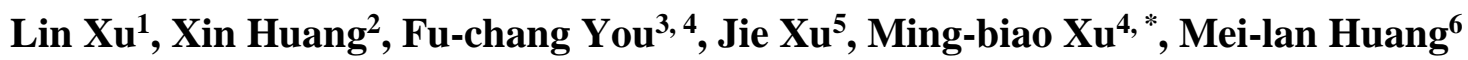

${ }^{1}$ College of Petrochemical and Energetic Engineering, Zhejiang Ocean University, Zhoushan 316022, China;

${ }^{2}$ College of Petroleum Engineering, China University of Petroleum(Beijing), Beijing 102249, China;

${ }^{3}$ Hubei Collaborative Innovation Center for Unconventional Oil and Gas, Yangtze University, Wuhan 430100, China;

${ }^{4}$ Jiahua Technology Co., Ltd, Jingzhou 434000, China;

${ }^{5}$ Institute of Exploration Techniques, Chinese Academy of Geological Sciences, Langfang, Hebei 065000, China;

${ }^{6}$ School of Chemistry and Chemical Engineering, Queen's University Belfast, Belfast BT95AG, United Kingdom;

\footnotetext{
* Corresponding author. Fax: +86 7168060863.

E-mail addresses: xuhu_11@yeah.net (M.-B. Xu).
} 


\section{ABSTRACT}

The supersaturated saline drilling fluid(SDF) with strong inhibition, as a novel alternative to anhydrite formation drilling, is crucial for the safe and economic drilling operation. In this work, a high performance supersaturated SDF was experimentally formulated in terms of the long anhydrite features of Missan Oilfields. Composite weighting approach involving liquid and solid materials was introduced to reinforce the inhibition of supersaturated SDF. A suite of laboratory tests was conducted to screen the essential viscosifiers and filtrate reducers, and optimize the formula of supersaturated SDF, by means of evaluating the basic rheological and filtration properties. The results showed that univalent salts $\mathrm{NaCl}, \mathrm{KCl}$, and $\mathrm{HCOONa}$ are utilized to formulate the multiple brine phase, and polymeric additives, VIS and S-FLO, are selected to improve rheological and filtration properties. The newly developed supersaturated SDF provides the excellent thermal stability, lubricity, as well as inhibition capability, which should be an instructive solution to minimize the hole problems in the anhydrite drilling.
\end{abstract}

Keywords: Anhydrite formation, Supersaturated brine, Weighted drilling fluid, High performance 


\section{Introduction}

Drilling through anhydrite formations is always challenging, due to the plastic deformation and cramping property of anhydrite, which can cause various drilling problems such as drilling fluid contamination, hole shrinkage, hole washout, hole collapse, and pipe sticking (Emmanuel et al. 2011; Wu et al. 2007). It has been established in the last decade that, drilling operation of anhydrite can be significantly improved by saltwater drilling fluids. Salts can dissolve in water necessitating the salinity of based fluid be kept near or at saturation to minimize wellbore enlargement (Dusseault et al. 2004; Akers et al. 2015; Jia et al. 2019). Therefore, the saline drilling fluid (SDF) play a crucial role in successful anhydrite drilling operations, which has also been one of the most widely used systems over the past decades.

SDFs are formulated with a brine as the liquid phase and selected polymers. The brine liquid phase may be composed of $\mathrm{NaCl}, \mathrm{KCl}, \mathrm{NH}_{4} \mathrm{Cl}, \mathrm{NaBr}, \mathrm{KBr}, \mathrm{HCOOK}, \mathrm{HCOONa}, \mathrm{CaCl}_{2}$, and $\mathrm{CaBr}_{2}$ as single or multiple brine solutions, with which the designated density can be attained from dissolved salts (Amer et al. 2016; Jin et al.2012; Kemp 1990). Selected polymers are, in general, added to offer appropriate suspension and required rheological properties (Knox et al. 2002; Zhou et al. 2015; Salkla and Mahto 2018). Generally, the higher the density of clear saline, the stronger the inhibition of drilling fluids can possess. To balance the formation pressure, a weighted SDF system involving solid weight agents appears to be necessary. The weighted SDFs can not only prevent and eliminate the plastic deformation and cramping behavior of anhydrite, but also effectively reduce drilling problems.

In spite of numerous studies on strongly inhibited SDFs, previous achievements should be limited for the complicated anhydrite formation. That is, the weighted drilling fluid needs to be especially designed on the basis of the detailed downhole conditions, for the purpose of meeting individual drilling requirements (Wajheeuddin et al. 2018). In addition to the necessary drilling fluid weight, the fluids type and specification need to be suitable to make sure no downhole problems happen while drilling the long anhydrite. Therefore, investigation on functional SDFs should be conducted, in combination to on the corresponding formation conditions and, in this case, the saline and additives should be selected in order to produce the multifunctional SDFs available in the target anhydrite. 
As a part of our ongoing study on SDFs (Xie et al. 2020), a novel supersaturated SDF has been designed and developed by lots of laboratory experiments, in terms of the features of anhydrite formation in Missan Oilfield. In this work, the supersaturated saline was exclusively employed to reinforce the fluid inhibition. The composite weighting manner was firstly defined, and then a suitable of polymeric additives were selected. Next that, the relevant amounts of additives were optimized by evaluating the properties of rheology and filtration under the simulated downhole conditions. Finally, the inhibition and lubricity of SDF were examined. These conclusions not only are meaningful to enrich a family of SDF available in anhydrite formation, but also will provide important technical reference for design on high performance working fluids.

\section{Methodology}

\subsection{Design of Supersaturated SDF}

\subsubsection{Supersaturated SDF construction}

Missan Oilfields was explored with a long section of anhydrite formation at about $2,000 \mathrm{~m}$. The downhole temperature is anticipated to be $100^{\circ} \mathrm{C}$, and the high formation pressure is inspected. To avoid potential drilling problems encountered in anhydrite formation, a novel supersaturated SDF with a density of $2.3 \mathrm{~s} . \mathrm{g}$ is designed, in which mixed-salt water involving organic and inorganic salts is employed as the weighted liquid to enhance the inhibition.

Construction of supersaturated SDF is given in Figure 1. As described above, the density control of SDF is essential, and thus the composite weighting approach concerning liquid and solid materials has been investigated. Note that, the focus of composite weighting approach is on analysis of liquid weighting materials and, in this regards, univalent salts and the relevant ratio were discussed. In addition, the key additives (e.g., viscosifier and filtrate reducer) were taken into account, in order to facilitate the performance of supersaturated SDF. Two steps constitute the majority of developing the basic formula of supersaturated SDF. Moreover, a series of lab tests was conducted to explore the applied properties of supersaturated SDF. At the same time, optimization tests of additive concentration were conducted to improve rheological and filtration properties. Finally, thermal stability, inhibition and lubricity were evaluated for meeting requirements of anhydrite formation drilling. 
Fig. 1 Schematic of constructing the supersaturated saline drilling fluid (SDF). The key process of constructing the supersaturated SDF are marked in yellow.

\subsubsection{Weighting approach}

Composite weighting approach mentioned above was adopted in the supersaturated SDF. It is well documented that the soluble univalent salts can effectively raise the liquid density, with which interstitial hydration of clays and rock cramping deformation may be prevented (Lin et al. 2011; Yang et al. 2013). Herein, typical univalent salts such as $\mathrm{NaCl}, \mathrm{KCl}$, and $\mathrm{HCOONa}$ were introduced as liquid weighting materials. To obtain the supersaturated solution, the excess salts were added. Undoubtedly, these univalent salts can cooperatively increase the density of continuous phase of SDF, which should contribute largely to the inhibition. Given the anhydrate pressure, the solid weighting material was synchronizedly employed to raise the density of supersaturated SDF up to 2.3s.g., wherein the conventional barite power was used as the weighting agent. Once the weighted liquid of supersaturated SDF was determined, functional additives were further screened and evaluated to determine the basic formula.

\subsection{Materials and tests}

\subsubsection{Materials}

Unless otherwise noted, functional additives were obtained from Jiahua Technology Co. Three typical kinds of viscosifers, including cellulose series, polyacrylamide series, and biopolymer series, and three kinds of filtrate reducers such as sulphonated series, starch series, and celluloses series, were used as received. some information on these commercial additives can be found in Table 1 . Note that, these functional reagents were widely employed in constructing the high performance drilling fluids. Sodium chloride $(\mathrm{NaCl})$, potassium chloride $(\mathrm{KCl})$, and sodium formate $(\mathrm{HCOONa})$ were purchased from Wuxi Jingke Fine Chemical Co.

Table 1 Information on additives applied here

\begin{tabular}{|c|c|c|}
\hline additives & ingredients & industry code \\
\hline liquid weighting materials & $\mathrm{NaCl}, \mathrm{KCl}, \mathrm{HCOONa}$ & \\
\hline viscosifiers & cellulose & CMC and PAC \\
\hline & polyacrylamide series & PLUS, PLH, and PHPA \\
\hline \multirow{2}{*}{ filtrate reducers } & biopolymer & XC, VIS, MC-VIS, and XAN \\
\hline & sulphonated series & SMP-I, SMPC, SMP-II, TEMP, and TX \\
\hline & starch series & CMS, HPS, B-LOSE, FLO, and S-FLO \\
\hline & cellulose & MIL, CMC-LV, and PAC-LV \\
\hline
\end{tabular}




\subsubsection{Tests of rheological and filtrate property}

The SDF system under consideration was firstly aged at $100^{\circ} \mathrm{C}$ for $16 \mathrm{~h}$., and then quench cooled for rheology and filtration tests. Rheological data of SDF system were measured at six specific shear rates, i.e., 600, 300, 200, 100, 6, and 3 rpm using a Fann 35 viscometer. American petroleum Institute (API) filtration was conducted with a ZNS-2 pressure filtration apparatus.

\subsection{Experimental process}

\subsubsection{Preparation of supersaturated SDF}

Table 1 provides the components of supersaturated SDF, and the preliminary formula is: fresh water $+2.0 \mathrm{wt} . \%$ filtrate reducer $+0.6 \mathrm{wt} . \%$ viscosifier + mixed-salt water, which is based on the previous studies. Apparently, the supersaturated SDF mainly contains viscosifier, filtrate reducers, the $\mathrm{pH}$ adjusting agent, the hardness control agent other than weighting materials, through which the comprehensive performance can be attained.

\subsubsection{Screening of key additives}

Viscosifier and filtrate reducers are always fundamental to develop high performance drilling fluids. Hence several typical kinds of additives were screened in terms of property of rheology and filtration within the simulated downhole environments. It should be pointed out that the rheology and filtration parameters, e.g., apparent viscosity (AV), plastic viscosity (PV), yield point (YP), and standard fluid loss (FLAPI) before and after aging process, were comparatively investigated here, in order to determine the basic formula of supersaturated SDF.

\subsubsection{Optimization of supersaturated SDF}

As for the supersaturated SDF preliminarily obtained, rheology and filtration properties were further optimized by a set of single-factor experiments. During the optimization process, dosages of key additives were varied in a certain range to determine an appropriate formula. In addition, test of thermal stability was conducted on the optimized system and the temperature changed in the range of $90 \sim 120^{\circ} \mathrm{C}$. Meanwhile, the properties of inhibition and lubricity were examined for the potential application on-site.

\section{Results and discussion}

\subsection{Construction of supersaturated SDF}

3.1.1 Analysis on weighting materials 
Previous studies have validated the application of solid-liquid composite weighting fluid in enhancing inhibition and density of drilling fluids (Wang et al. 2009; Jiang et al. 2014; Li et al. 2011). The weighting capability of supersaturated solution can be further reinforced by mixing inorganic and organic salts. Herein, univalent salts, $\mathrm{NaCl}, \mathrm{KCl}$, and $\mathrm{HCOONa}$, are typically utilized to construct the supersaturated state. In the investigated univalent salts, $\mathrm{NaCl}$ is the main composition of the saturated solution, and $\mathrm{KCl}$ and $\mathrm{HCOONa}$ are further introduced to improve the inhibition. The compositions of basic saline are given as: fresh water $+30 \mathrm{wt} . \% \mathrm{NaCl}+6 \mathrm{wt} . \% \mathrm{KCl}$ $+8 \mathrm{wt} . \%$ HCOONa, and the density of supersaturated solution can be controlled at $1.23 \mathrm{s.g}$.

Undoubtedly, such supersaturated solution involving composite salts can not only work as the basic continuous phase for drilling fluids, but also reinforce the weighting and inhibition properties. Moreover, the solid weighting material, i.e., barite, is introduced to raise the density of drilling fluid to $2.3 \mathrm{s.g}$. As a result of composite weighting, the cramp of anhydrite upon drilling can be prevented or even eliminated, and wellbore stability of the anhydrate formation can be obtained.

\subsubsection{Screening of viscosifiers}

Viscosifiers are fundamental to modify rheology of multifunctional drilling fluids. To ascertain a suitable viscosifier, we investigated three representative kinds of viscosifiers consisting of cellulose(CMC and PAC), polyacrylamide (PLUS, PLH, and PHPA), and biopolymer(XC, VIS, MC-VIS, and XAN), and comparatively analyzed the rheological and filtration property of supersaturated SDF formulated here. Note that, the formula of supersaturated SDF was: fresh water $+0.6 \mathrm{wt} . \%$ viscosifier $+(30 \mathrm{wt} . \% \mathrm{NaCl}+6 \mathrm{wt} . \% \mathrm{KCl}+8 \mathrm{wt} . \% \mathrm{HCOONa})$ mixed-salt water.

Fig. 2 Comparison of rheological property for the SDFs formulated with different viscosifiers. Three typical kinds of visicosifers were investigated and means of some characteristic parameters (A) AV, (B) PV, (C) YP, and (D) $6 \mathrm{rpm}$ readings (Ф6) were presented. Data are shown as mean \pm s. e. $\mathrm{m} .(\mathrm{n}=3$, replicates).

Fig. 2 presents typical rheological and filtrate data of the investigated SDF, including AV, PV, YP, and 6 rpm readings (Ф6). Based on performance requirements of drilling fluid, AV and PV are crucial to the cycling property, while YP and $\Phi 6$ contribute largely to the capability of carrying cutting upon drilling. It is clear in Fig. 2 that after an aging treatment, all of the rheological data 
decreased, meaning that the aging process can influence chemical functional groups of polymeric additives and rheological property of fluid (Yang et al. 2019). For example, AV and PV of the SDFs with polyacrylamide and cellulose series were tested to decrease by about $50 \%$ after aging. In contrast with polyacrylamide and cellulose series, biopolymers exhibited a better aging-resistant property, as can be seen in Fig. 2. The rheological data of the SDFs with biopolymers exhibited a slight decrease after aging. In particular, the low shear rate reading (i.e., Ф6) can be detected (see Fig. 1D), while $\Phi 6$ of other specimen were tested to be 0 . The fact indicated that biopolymer series should possess more excellent salt-resistant capacity relative to polyacrylamide and cellulose series. Such salt-resistant capacity should be attributed to special steric configuration of biopolymers. There are lots of side groups in the biopolymers, which will prevent dehydration and sediment of polymers in brine. As a result, the thickening property of biopolymers can be maintained for the designed SDFs. Meanwhile, one can find that in the biopolymers studied here, VIS exhibited the most prominent rheological modification, and can meet both rheology and cutting carrying requirements. Therefore, VIS was selected as the viscosifier for further construction of the supersaturated SDF.

\subsubsection{Screening of filtrate reducers}

Filtrate reducer is another kind of additives to drilling fluids, which is of much importance in improving the filtration property. To determine a moderate filtrate reducer, similarly, three kinds of filtrate reducers involving sulphonated specimen (SMP-I, SMPC, SMP-II, TEMP, and TX), starch specimen (CMS, HPS, B-LOSE, FLO and S-FLO), and celluloses specimen (MIL, CMCLV and PAC-LV) that are usually employed in construction of drilling fluid, were systematically investigated, by means of evaluating their effect on rheological and filtrate performance. The testing results are presented in Fig. 3. Note that, the formula of supersaturated SDF is given as follows: fresh water +2.0 wt. $\%$ filtrate reducer +0.6 wt. $\%$ VIS $+(30$ wt. $\% \mathrm{NaCl}+6$ wt. $\% \mathrm{KCl}+8$ wt. $\%$ HCOONa) mixed-salt water, wherein the selected viscosifier, VIS, are used here.

Fig. 3 Comparison of rheological and filtrate property for the SDFs formulated with different filtrate reducers. Three kinds of filtrate reducers were investigated and means of some characteristic parameters (A) AV, (B) PV, (C) YP, (D) 6 rpm readings (Ф6), and (E) FLAPI were presented. Data are shown as mean \pm s. e. $m .(n=3$, replicates $)$. 
In Fig. 3, all of the rheological data have a minor increasement with an incursion of filtrate reducers, and thus this finding reveals that filtrate reducers can vary the rheology of the SDF to some degree. Given the long-chain configuration of filtrate reducers, not surprisingly, the fluid viscosity can increase, due to adsorption effect of end chains (Elkatatny 2019). In principle, the additives are expected with unique function, which would be useful for the facile control of fluid property. Accordingly, it is necessary to select the filtrate reducers with weak thickening character. In the considered filtrate reducers, S-FLO and sulphonated series displayed weaker thickening effect, and appeared to be more appropriate than others. Meanwhile, S-FLO and sulphonated series can effectively maintain $\Phi 6$, which enable strong suspension capability of fluid. Moreover, a comparison of FLAPI showed that S-FLO should be more suitable than sulphonated series, due to a lower FL $\mathrm{API}_{\mathrm{AP}}$. Based on weak thickening property and stronger capability of depressing filter loss, S-FLO was selected as a proper filtrate reducer for the construction of supersaturated SDF.

\subsection{Optimization of supersaturated SDF}

\subsubsection{Viscosifier concentration}

VIS concentration was further optimized for future field application. Similar to tests of additive selection, the rheological and filtrate properties were pursued upon optimization. The testing results are shown in Fig. 4. Note that, the formula of supersaturated SDF is given as: fresh water +0.25 wt. $\% \mathrm{Na}_{2} \mathrm{CO}_{3}+0.10$ wt. $\% \mathrm{NaOH}+(30$ wt. $\% \mathrm{NaCl}+6$ wt. $\% \mathrm{KCl}+8$ wt. $\% \mathrm{HCOONa})$ mixed-salt water $+(0 \sim 0.4$ wt. $\%)$ VIS +2.0 wt. $\%$ S-FLO + barite, wherein the fluid density was increased to 1.23 s.g. in terms of in-field requirement.

Fig. 4 presents AV, PV, YP, $\Phi 6$, and FLAPI of the supersaturated SDF while varying VIS concentration in the range of $0 \sim 0.4 \mathrm{wt}$.\%. According to data variation shown in Fig. 2, one can notice two trends that (1) rheological parameters became much larger, and (2) filtrate losses decreased with an increment of the VIS concentration. In Fig. 4A, fluid viscosity displayed a dramatic increase with the VIS concentration. For example, the increasing magnitude of $\mathrm{AV}_{\mathrm{t}}$ and $\mathrm{PV}_{\mathrm{t}}$ are as high as $138 \%$ and $35 \%$, respectively, while varying the concentration from 0 to $0.4 \mathrm{wt} . \%$. This result is well consistent with previous studies performed by Hakiki et al. (Hakiki et al. 2015). An increase of the concentration of polymer additive will inevitably lead to the increasing intermolecular entanglement. As a result, influence of brine on the polymer chain and fluid viscosity 
can be retarded by effect of concentration compensation. Considering the pumping capacity onsite, on one hand, $\mathrm{AV}_{\mathrm{t}}$ should be less than $60 \mathrm{mPa} \cdot \mathrm{s}$ and, thus, the addition of VIS are recommended to be $0.2 \mathrm{wt} . \%$. On the other hand, while the VIS concentration is of $0.2 \mathrm{wt} . \%$, the mean values of PV and $\Phi 6$ are $9 \mathrm{~Pa}$ and 2.8 (see Fig. 4B and 4C), respectively, indicating that the cutting suspension capability can be obtained for the designed fluid. In Fig. 4D, one can observe that the decrease of filtrate loss focuses on the concentration range of $0 \sim 0.2 \mathrm{wt} . \%$, reflecting a limited impact on filtrate loss by increasing the VIS concentration. Hence the VIS concentration is proposed to be $0.2 \mathrm{wt}$. $\%$, in combination with rheological and filtrate loss analyses.

Fig. 4 Effect of viscosifier (VIS) concentration on rheological and filtrate property of the supersaturated SDF: (A) viscosity (AV and PV), (B) YP, (C) 6 rpm readings (Ф6), (D) FLAPI. Data are shown as mean \pm s. e. $m$. ( $n=3$, replicates). The subscript " 0 " and " $t$ " separately correspond to the tested system without and with aging treatment.

\subsubsection{Filtrate reducer concentration}

Influence of S-FLO concentration on rheological and filtrate loss property was also investigated. It will be instructive to help improve the formula of supersaturated SDF. According to the results achieved above, the relative formula was given as: fresh water +0.25 wt. $\% \mathrm{Na}_{2} \mathrm{CO}_{3}+0.1$ wt. $\%$ $\mathrm{NaOH}+(30$ wt. $\% \mathrm{NaCl}+6$ wt. $\% \mathrm{KCl}+8$ wt. $\% \mathrm{HCOONa})$ mixed-salt water $+(1.5 \sim 3.0 \mathrm{wt} . \%) \mathrm{S}-$ FLO + 0.2 wt.\%VIS + barite, wherein S-FLO concentration varied in the range of 1.5 3.0 wt.\%, and the fluid density was increased to $1.23 \mathrm{s.g}$. in terms of in-field requirement.

Fig. 5 Effect of filtrate reducer (S-FLO) concentration on rheological and filtrate property of the supersaturated SDF: (A) viscosity (AV and PV), (B) YP, (C) 6 rpm readings (Ф6), (D) FL API. Data are shown as mean \pm s. e. $m$. ( $n=3$, replicates). The subscript " 0 " and " $\mathrm{t}$ " separately correspond to the tested system without and with aging treatment.

AV, PV, YP, Ф6, and FL API of the supersaturated SDF were given in Fig. 5. As might be anticipated, all of the rheological data increase with increasing S-FLO concentration. Besides, the magnitudes of data variation in the aged specimen are remarkably higher than those in the initial specimen. In the S-FLO concentration range investigated here, for example, the variation magnitudes of $\mathrm{AV}_{0}$ and $\mathrm{AV}_{\mathrm{t}}$ were $17 \%$ and $8 \%$ (see Fig. 5A), respectively. Obviously, the aged 
temperature plays an important role in determining stability of supersaturated SDF. In Fig. 5D, FLAPI reduced with an increment of S-FLO concentration, which can be mainly attributed to the stronger intermolecular entanglement. It is worthwhile to remark that while the S-FLO concentration is of 3 wt.\%, FLAPI was tested to be less than $7.5 \mathrm{ml}$, meeting the industrial requirement. Meanwhile, one can facilely find that for the constructed SDF with 3 wt.\% S-FLO, moderate YP and $\Phi 6$ that are related with suspension capability of fluid can be obtained. In views of results obtained above, the S-FLO concentration is recommended to be $3.0 \mathrm{wt} . \%$. Therefore, the optimized formula of supersaturated SDF is: fresh water+ 0.25 wt. $\% \mathrm{Na}_{2} \mathrm{CO}_{3}+0.10$ wt. $\% \mathrm{NaOH}$ $+(30$ wt. $\% \mathrm{NaCl}+6$ wt. $\% \mathrm{KCl}+8$ wt. $\% \mathrm{HCOONa})$ mixed-salt water+ 3.0 wt. $\% \mathrm{~S}-\mathrm{FLO}+0.2$ wt. $\%$ VIS + barite (1.23 s.g.).

\subsection{General applied properties}

\subsubsection{Analysis on thermal stability}

To meet the drilling operation on-site, thermal stability of the formulated supersaturated SDF was evaluated in the range of $90 \sim 120^{\circ} \mathrm{C}$. Herein, only the relationships between rheological and filtrate data and temperature of the aged specimen are given in Fig. 6.

Fig. 6 Effect of temperature on rheological and filtrate property of the supersaturated SDF: (A) viscosity (AV and PV), (B) YP, (C) 6 rpm readings (Ф6), (D) FLAPI. Data are shown as mean \pm s. e. $m .(n=3$, replicates $)$.

As follows from the data present in Fig. 6, the rheological parameters will decline with the elevated temperature, but reverse tendency can be observed for the filtrate parameters. For example, as the temperature varied from $90^{\circ} \mathrm{C}$ to $120^{\circ} \mathrm{C}, \mathrm{AV}, \mathrm{PV}, \mathrm{YP}$, and $\Phi 6$ reduced by $10 \%, 10 \%, 12 \%$ and $36 \%$, respectively, while FLAPI increased by $10 \%$. The property changes can be partially ascribed to thermal degradation of polymeric additives (Sreekumar 2014), which can make property of drilling fluid bad. Although a certain variation happened, these characteristic parameters were still at an acceptable level, implying that the supersaturated SDF constructed here has proper thermal stability in the investigated temperature range.

\subsubsection{Analyses on inhibition and lubricity}

It is generally known that for the drilling fluids, the inhibition and lubricity is significant for safe and economic drilling. Note that, the inhibition is closely related with wellbore stability, and 
the lubricity contributes largely for reducing torque and friction. Consequently, two properties of supersaturated SDF were examined.

As for the supersaturated SDF, the recovery rate of solid phase arrives up to $93.35 \%$, indicating excellent property of cuttings dispersion and cuttings hydration prevention. Additionally, the friction coefficient of supersaturated SDF is of 0.17 , which is less than that of the common waterbased muds, suggesting better lubricity relative to the general water-based muds. In view of these conclusions achieved, it can be concluded that the supersaturated SDF is developed with excellent performance, which would be a novel alternative to anhydrite formation drilling.

\section{Conclusions}

Drilling through anhydrate formations is generally challenging due to wellbore stability problems. In the present work, a novel supersaturated saline drilling fluid that can be used to drill anhydrates has been designed and developed, in combination with characteristics of the long anhydrate in Missan Oilfields. The liquid-solid composite weighting manner was utilized, and supersaturated saline containing three kinds of univalent salts was employed to reinforce the inhibition of drilling fluid. The filtrate reducer and viscosifier were experimentally selected, and the relative concentrations were also optimized by evaluation on rheology and filtration loss. The inhibition and lubricity of supersaturated saline drilling fluid were measured. The formulated supersaturated saline drilling fluid exhibits excellent rheology, filtration property, as well as excellent inhibition and lubricity properties, which would be a novel alternative to anhydrate formation drilling. These conclusions can not only facilitate improvement of supersaturated saline drilling fluid, but also extend a new family of drilling fluids available in anhydrate formations.

\section{Acknowledgements}

The authors thank the Welfare Technology Research Project of Zhejiang Province (No. LGG20E040002), Educational Commission General Project of Zhejiang Province(No. Y201840431), and Zhoushan Science and Technology Plan Project(2019C21006) for financial support.

\section{References}


[1] Omojuwa, E.O.; Osisanya, S.O.; Ahmed, R.: Properties of salt formations essential for modeling instabilities while drilling. In: SPE Nigeria Annual International Conference and Exhibition, Society of petroleum engineers (2011). https://doi.org/10.2118/150801-MS

[2] Wu, H.; Zhang, K.M.; He, S.G.: Drilling fluid for salt-gypsum beds in deep wells in Tahe Oilfield. TUHA Oil \& Gas. 12(2), 169-174 (2007)

[3] Dusseault, M.B.; Maury, V.; Sanfilippo, F.; Santarelli, F.J.: Drilling through salt: constitutive behavior and drilling strategies. In: ARMA-04-608 presented at 6th North America Rock Mechanics Symposium, Houston, Texas (2004)

[4] Akers, T.J.: Salinity-based pump-and-dump strategy for drilling salt with supersaturated Fluids. SPE Drill and Compl. 26(1), 1-9 (2011). https://doi.org/10.2118/128405-PA

[5] Jia, H.; Hu, Y.X.; Zhao, S.J.; Zhao, J.Z.: The feasibility for potassium-based phosphate brines to serve as high-density solid-free well-completion fluids in high temperature/ high-pressure formations. SPE Journal. 24(5), 1-14 (2019). https://doi.org/10.2118/194008-PA

[6] Amer, A.; Dearing, H.; Jones, R.; Sergiacomo, M.: Drilling through salt formations: a drilling fluids review. In: SPE-180326-MS presented at deepwater drilling and completions conference, Galveston, Texas (2016). https://doi.org/10.2118/180326-MS

[7] Jin, C.P.; Ma, G.C.; Wang, C.S.; Ou, Y.W.; Li, W.; He, H.; Wang, L.; Wang, X.B.: The Application of Polymer-sulfonated Saturated Salt Based Mud System on the Right Bank of the Amu Darya in Turkmenistan. In: IADC/SPE Asia Pacific Drilling Technology Conference and Exhibition, Society of petroleum engineers (2012). https://doi.org/10.2118/155685-MS

[8] Kemp, N.P.: Mutual solubility of salts in drilling and completion fluids. SPE Drilling Engineering. 5(1), 21-26 (1990). https://doi.org/10.2118/16688-MS

[9] Knox, D.; Bye, G.K.; Horton, R.; Svoboda, C.; Foxenbr, W.; Tresco, K.: Application of a novel, high-density, brine-based, biopolymer-free reservoir drilling fluid: a case study. In: SPE-73765MS presented at International symposium and exhibition on formation damage control, Lafayette, Louisiana (2002). https://doi.org/10.2118/73765-MS

[10] Aizuddin, S.; Ahmad, K.I.: Effects of surfactant-polymer formulation and salinities variation towards oil recovery. Arab. J. Sci. Eng. 39, 4251-4260 (2014). http://doi.org/10.1007/s13369014-1025-7 
[11] Zhou, H.; Deville, J.P.; Davis CL. Novel thermally stable high-density brine-based drill-in fluids for HP/HT application. In: SPE-172659-MS presented at SPE Middle East Oil \& Gas Show and Conference, Manama, Bahrain (2015). https://doi.org/10.2118/172659-MS

[12] Salkla, T.; Mahto, V. Experimental investigations and optimizations of rheological behavior of dirlling fluids using RSM and CCD for Gas hydrate-bearing formation. Arab. J. Sci. Eng. 43, 6541-6554 (2018). http://doi.org/10.1007/s13369-018-3292-1

[13] Wajheeuddin, M.; Hossain, M.E.: Development of an envirnmentally-friendly water-based mud system using natural materials. Arab. J. Sci. Eng. 43, 2501-2513 (2018). http://doi.org/10.1007/s13369-017-2583-2

[14] Xie, C.L.; Wang, Z.Y.; Qiu, Y.; Gou, G.z.; Gao, J.F.; Yin, G.; Wu, Y.;. Safe Drilling Technology of High Pressure Salt Paste Formation in Halfaya Oilfield, Iraq. Journal of Jilin $\begin{array}{lllll}\text { University(Earth } & \text { Science } & \text { Edition). } & \text { 50(2), } & \text { 589-597 }\end{array}$ http://xuebao.jlu.edu.cn/dxb/CN/Y2020/V50/I2/589

[15] Lin, W.J.; Huang, Z.Y.; Zhuang, Y.D.: Maintenance technology of high-density saturated brine drilling fluid during drilling into salt-gypsum layer. Natural Gas Exploration \& Development. 34(1), 64-67 (2011)

[16] Yang, P.; Lv, K.H.; Zhen, P.P.; Hong, W.: Laboratary research on saturated salt water based clay-free drilling fluids with thermal stability. Oilfield Chemistry. 4, 482-485 (2013). http://doi.org/10.19346/j.cnki.1000-4092.2013.04.002

[17] Hu, W.J.; Luo, P.Y.; Bai, Y.; Lin, L.: Study on a new high temperture high density saltwater drilling fluid. Drilling Fluid \& Comletion Fluid. 34(3), 1-10 (2017). http://doi.org/10.3969/j.issn.1001-5620.2017.03.001

[18] Li, J.; Zhao, C.X.; Lv, E.C.; Hu, J.P.; Xu, G.H.: Characteristics of formate and organic salt base fluid. Drilling Fluid and Completion Fluid. 28(4), 72-77 (2011)

[19] Yang, Z.; Zhang, X.; Yu, J.; Xu, W.: Effects of aging on the multiscale properties of SBSmodified asphalt. Arab. J. Sci. Eng. 44, 4349-4358 (2019). http://doi.org/10.1007/s13369-018$3399-4$

[20] Elkatatny, S.: Enhancing the rheological properties of water-based drilling fluid using micronized starch. Arab. J. Sci. Eng. 44: 5433-5442 (2019). http://doi.org/10.1007/s13369-019- 
03720-1

[21] Hakiki, F.; Maharsi, D.A.; Marhaendrajana, T.: Surfactant-polymer coreflood simulation and uncertainty analysis derived from laboratory study. Journal of Engineering and Technological Sciences. 47(6), 706-725 (2015). http://doi.org/10.5614\%Fj.eng.technol.sci.2015.47.6.9

[22] Hakiki, F.; Salam, D.D.; Akbari, A.; Nuraeni, N.; Aditya, W.; Siregar, S. Is epoxy-based polymer suitable for water shut-off application? In: SPE-176457-MS presented at SPE/IATMI Asia Pacific Oil \& Gas Conference and Exhibition, Bali, Indonesia (2015). https://doi.org/10.2118/176457-MS

[23] Sreekumar, P.A,; Elanamugilan, M.; Singha, N.K.; Al-Harithi, M.A,; De, S.K.; Al-Juhani, A.: LDPE filled with LLDPE/starch materbatch: rheology, morphology and thermal analysis. Arab. J. Sci. Eng. 39: 8491-8489 (2014). http://doi.org/10.1007/s13369-014-1467-y 


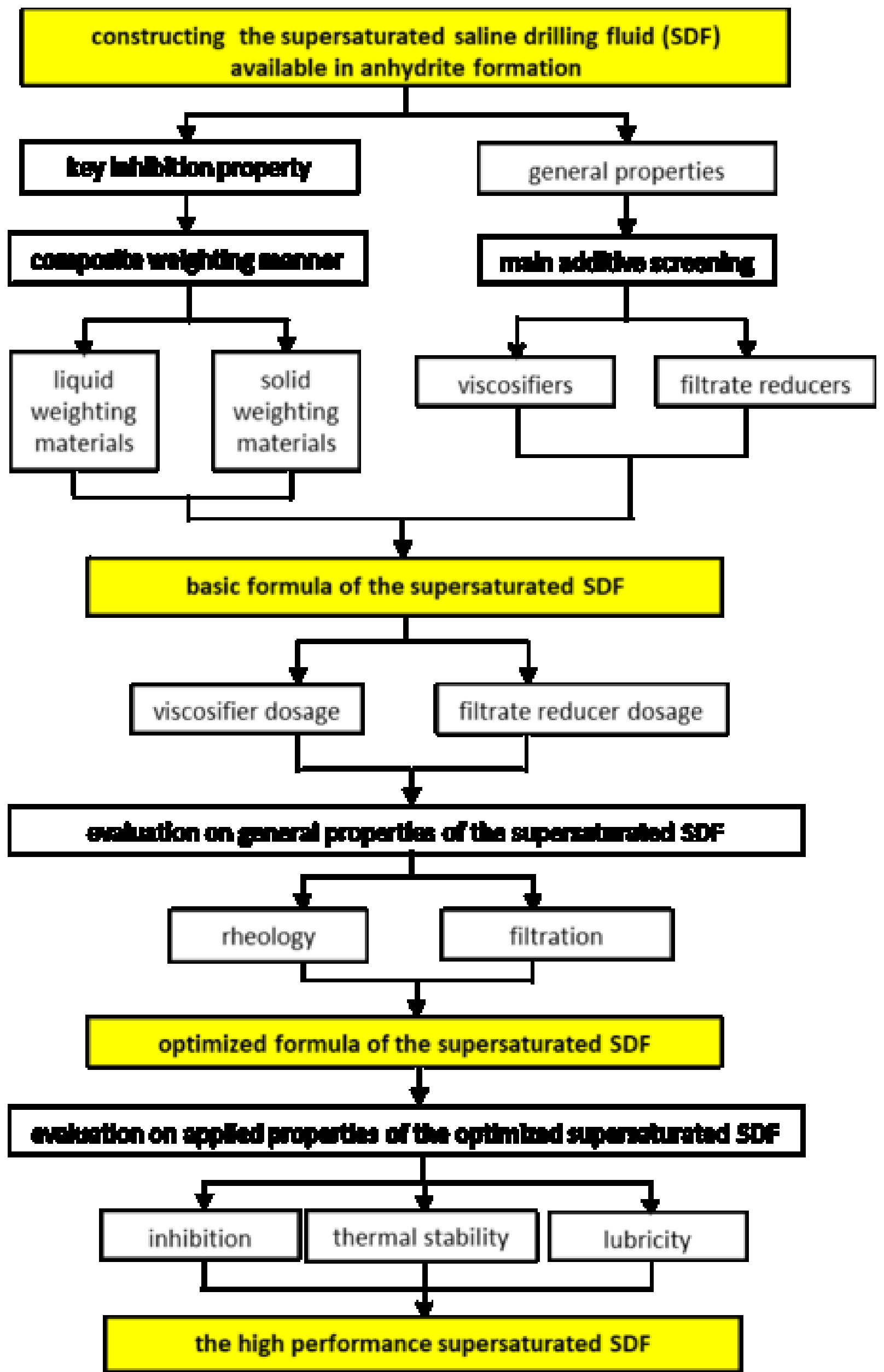



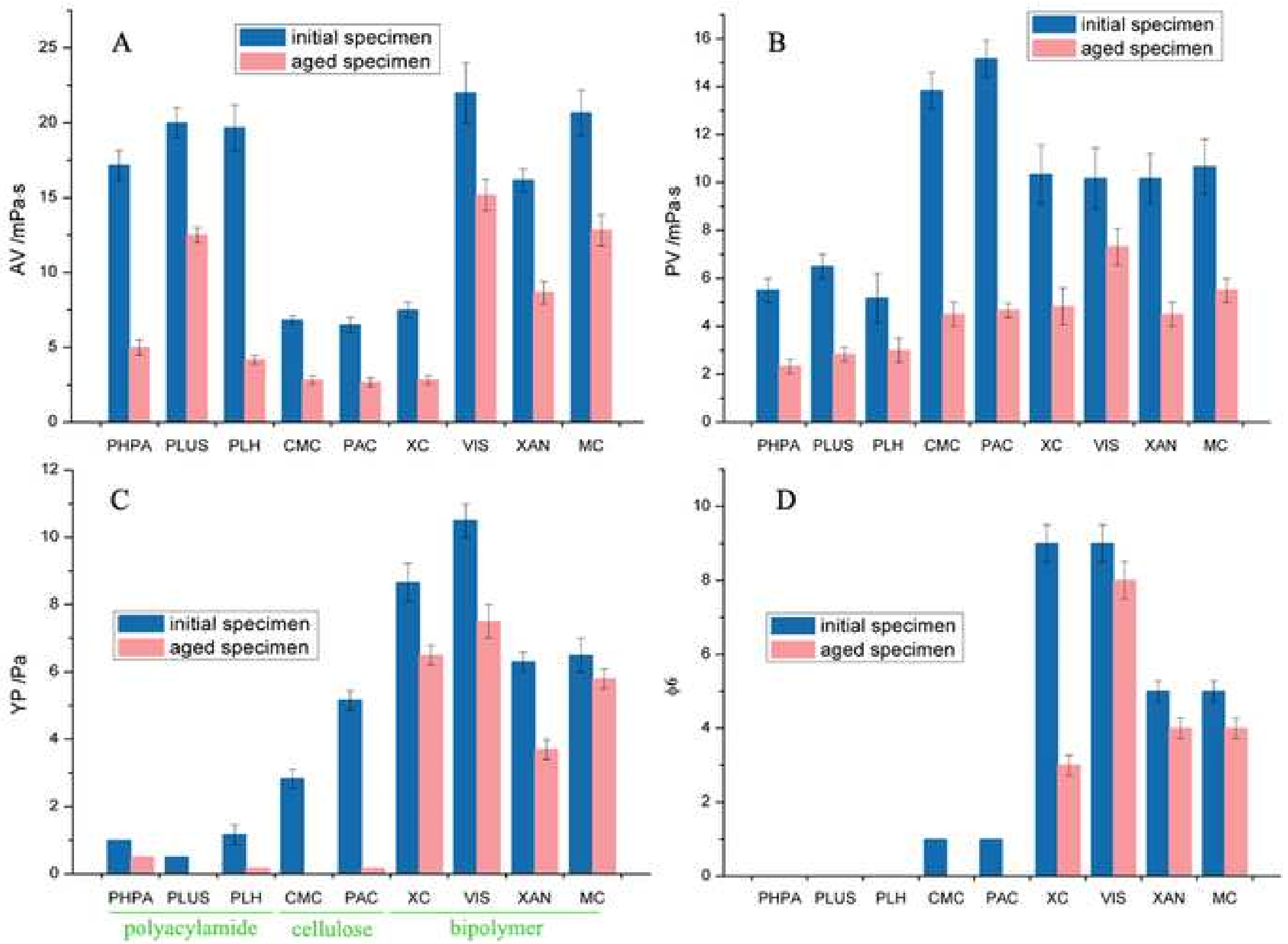

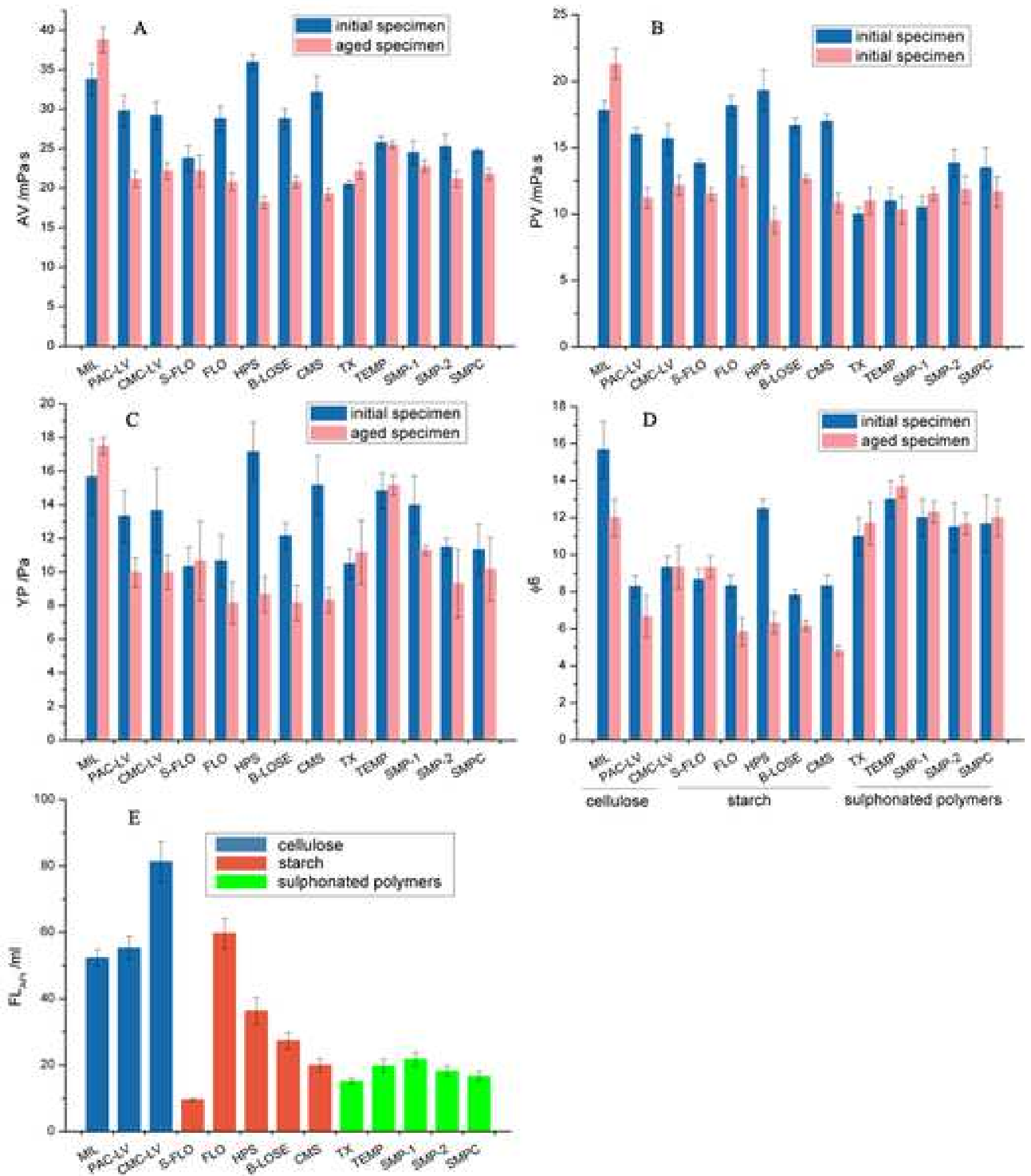

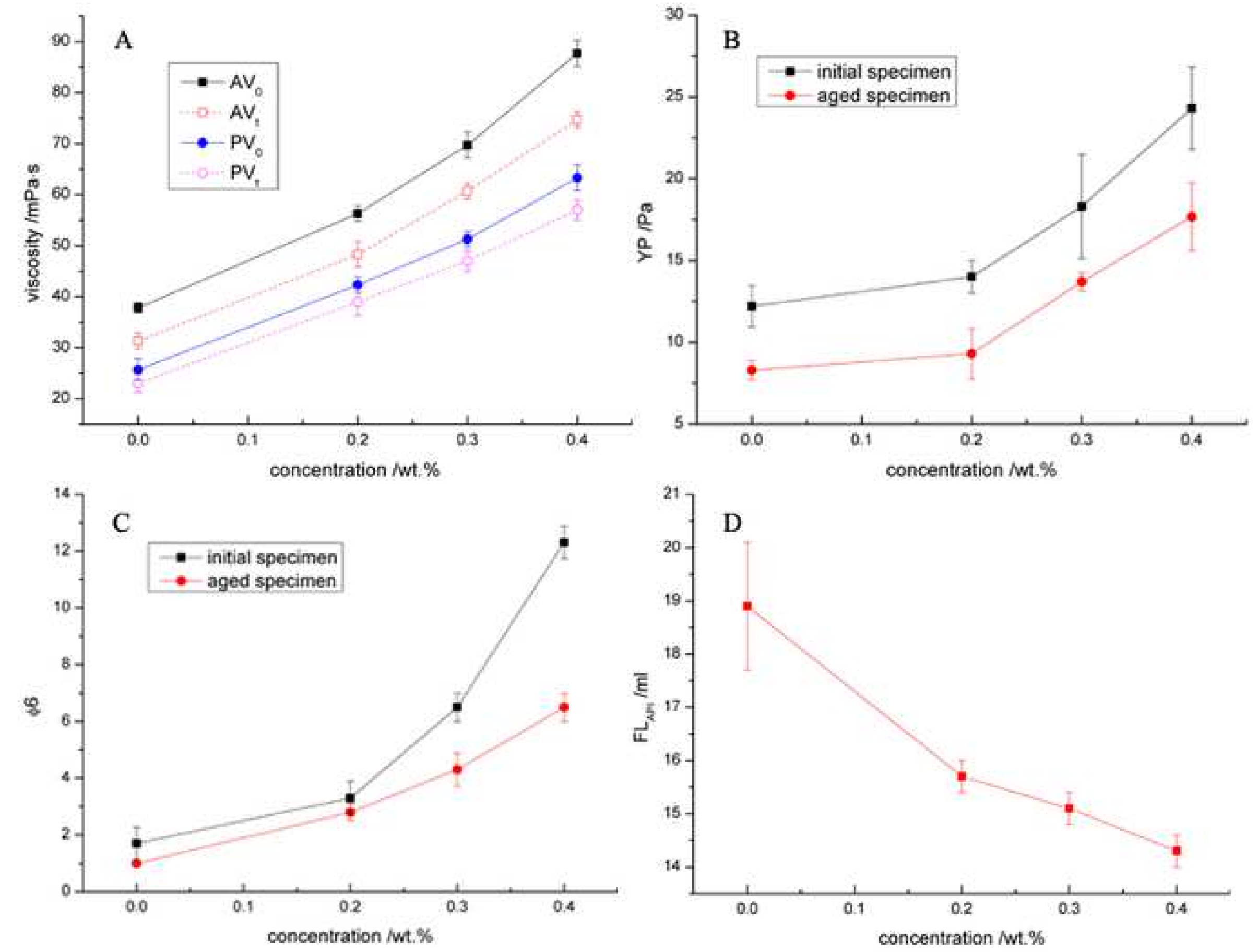

concentration $/ \mathrm{wt} . \%$

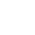


Dear Reviewers:

We are truly grateful to your critical comments and thoughtful suggestions. Based on these comments and suggestions, we have made careful modifications on the original manuscript and, in particular, the section of "result and discussion" has been partially rewritten. Below you will find our point-by-point responses to the comments (or questions). In the paper, all the modified parts are marked in red. 


\section{Response to comment:}

\section{Reviewer \#1}

\section{Comment 1:}

\section{Fig 1:}

- Please explain in the caption what do the color codes mean? - Green, yellow, white boxes and the lines.

- Please put all abbreviations in the caption as well even though you have already mentioned them in the paper, e.g. SDF.

- Put space in before ( to be saline drilling fluid (SDF).

- AIM equals to purpose?

- No need all capital if it is not an abbreviation. - Start all word with capital (standardize them)

Response: According to this advice, Fig.1 has been re-presented, and the improper caption has been modified; the color code has been remarked and explained for better understanding; all abbreviations involved in the paper have been elucidated; space has been added;

\section{Comment 2:}

Fig 2: Please show the error bars. State in the caption the repeatability. Please put in the caption the full name of each chemicals (abbreviations).

Response: According to this advice, some experiments have been complemented, and error bars have been given in Fig. 2 to state the repeatability. The abbreviations of chemicals are the industrial codes, and they have been introduced in Table 1. 


\section{Comment 3:}

Fig 3:

- Please show the error bars. State in the caption the repeatability.

- So, black and red refer to left? Put arrow - Write the word legend next to the curve (no need inside a box)

- Legend must use same color as the curve color

Response: According to these advices, Fig. 3 has been reconstructed in the form of bar error. Some improper description has been eliminated. Some detailed information can be found in P14.

\section{Comment 4:}

I found many () or [] and you do not use space before ( or [. Please give a space.

Response: According to this advice, we checked the paper and the lost space has been added before all () or [].

\section{Comment 5:}

Please move all Tables 2-5 into a SUPPLEMENTARY INFORMATION (SI). Show in the paper as figures or bar charts; with known error bar and repeatability.

Response: According to this advice, Tables 2-5 have been provided as a supplementary information together with complementary experiments, and some key information such as rheological and filtrate data has been given in the form of bar chart. The detailed description can be found in the section "results and discussion" in P8-P15.

\section{Comment 6:}


Please consider more papers $>7$ from this journal itself. What is the suitability merit to get published here if there is no attachment of references to this journal itself?

Response: Arab. J. Sci. Eng. has involved limited papers on brine drilling fluid system. According to your advice, we have made an effort to cite 6 papers that are contacted with the present work from this journal.

\section{Comment 7:}

Please note that the presence of salts may break the polymer or viscosifier chain and results in a lower viscosity; and viscosity increases with increasing polymer concentrations due to the increasing intermolecular entanglement.

Response: According to this advice, we have provided simple description on relation of polymer concentration and intermolecular effect, and cited Hakiki's work.

\section{Comment 8:}

Please note that the viscosity of fluids is shear-rate dependent. Please declare not only the unit mPa.s but also measured at what shear rate? (1/s)

Response: As for rheological property of drilling fluids, the viscosity is always tested with a 6-speed rotator apparatus, which can exhibit relation between viscosity and shear rate. To clarify this point, we have supplied the experimental process in P6.

\section{Comment 9:}

Regarding comment \#7 and \#8 above, please cite and consider these papers in your references: - Hakiki, F, Maharsi, DA, Marhaendrajana, T. 2015. Surfactant-polymer coreflood simulation and uncertainty analysis derived from laboratory study. Journal of Engineering and Technological Sciences 47 (6), 706-725. DOI: 
http://dx.doi.org/10.5614\%2Fj.eng.technol.sci.2015.47.6.9 - Hakiki et al. 2015. Is Epoxy-Based Polymer Suitable for Water Shut-Off Application? SPE-176457-MS. DOI: $\underline{\text { htps://doi.org/10.2118/176457-M }}$

Response: These two papers are instructive to our work, and we have cited them in the section of "screening of viscosifier".

\section{Comment 10:}

Make sure all references are mentioned in the paper passage and also provide the DOI link (if any).

Response: all references have been mentioned, and the DOI link (if any) has been provided.

\section{Comment 11:}

In the optimization process, please show in new figures the variables you played with.

Response: New figures linked with the optimization process were presented in "results and discussion".

\section{Comment 12:}

So, which one is the best viscosifier, filtrate reducer, and VIS content? At what concentrations? Could you please create a 3D map optimization? Please give a case study with a given reservoir properties to handle with.

Response: The advice would be helpful to explicitly determine the optimized ingredient, but it will inevitably demand a large quantity of experiments. To meet the requirement on-site, a single-factor experiment is enough and moderate, which is also cost-effective in building appropriate formula. Using the single-factor method, we 
attained the optimized formula of saturated SDF: fresh water+ 0.25 wt. $\% \mathrm{Na} 2 \mathrm{CO} 3+$ 0.10 wt. $\% \mathrm{NaOH}+(30$ wt. $\% \mathrm{NaCl}+6$ wt. $\% \mathrm{KCl}+8$ wt. $\%$ HCOONa) mixed-salt water+ 3.0 wt. $\%$ S-FLO + 0.2 wt. $\%$ VIS + barite (1.23 s.g.).

In addition, according to the advice, the title of paper has been modified as "Experimental Investigation into A Novel Supersaturated Saline Drilling Fluid Available in Anhydrite Formation: A Case study of Missan Oilfield, Iraq” 


\section{Reviewer \#2}

Comment 1: The experimental part should be supplemented with a description of the experimental procedure used to analyze the dispersion of the drilling fluid, that is, measuring viscosity and fluid loss.

Response: According to this helpful advice, we have complemented experimental procedure.

Comment 2: The article also presents a wide range of different thickeners and filtrate reducing agents. The composition of all types of additives should be described or referred to.

Response: All types of additives are commercially used in petroleum industry, and we presented a description on additive composition in Table 1. 

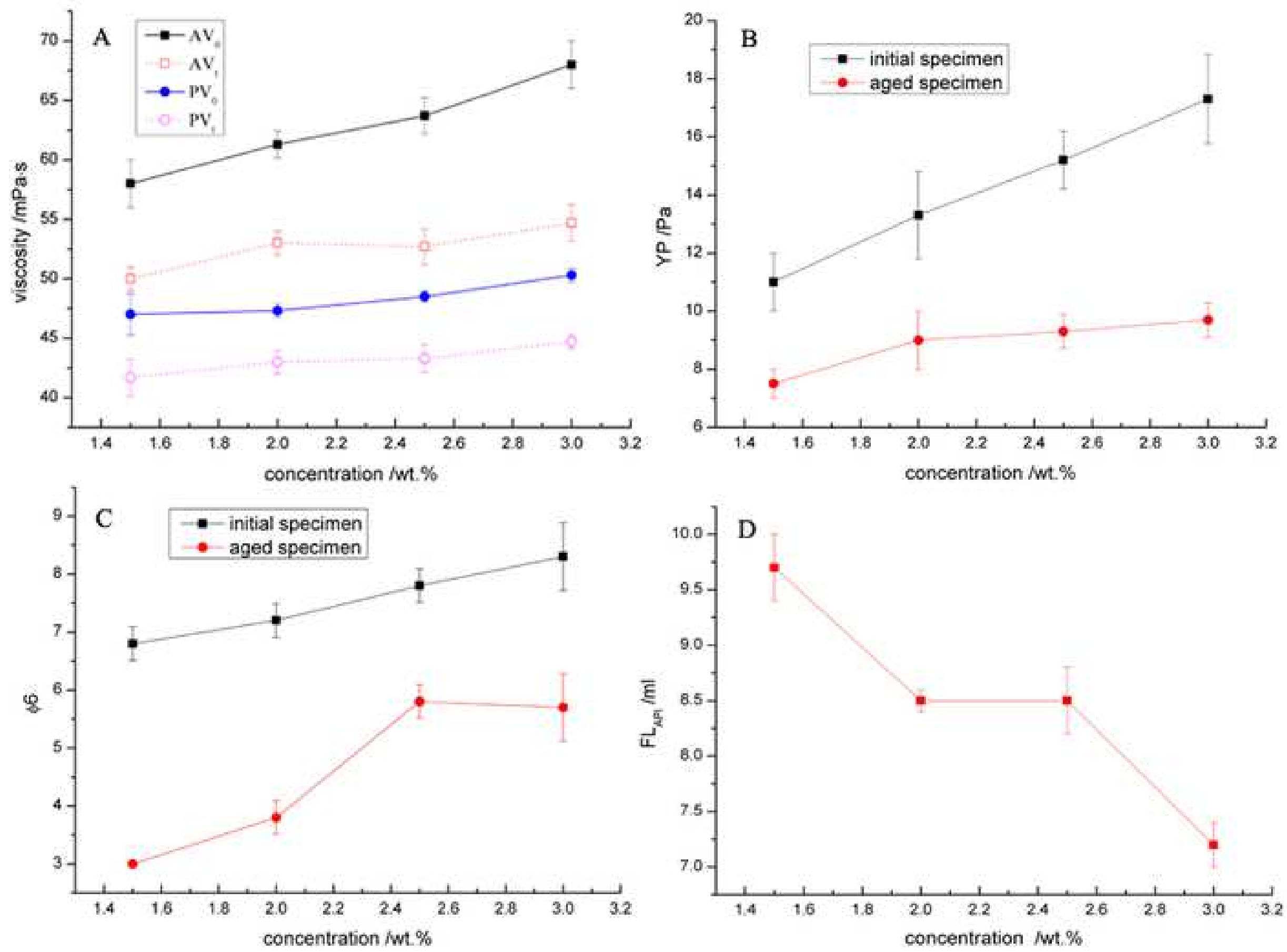

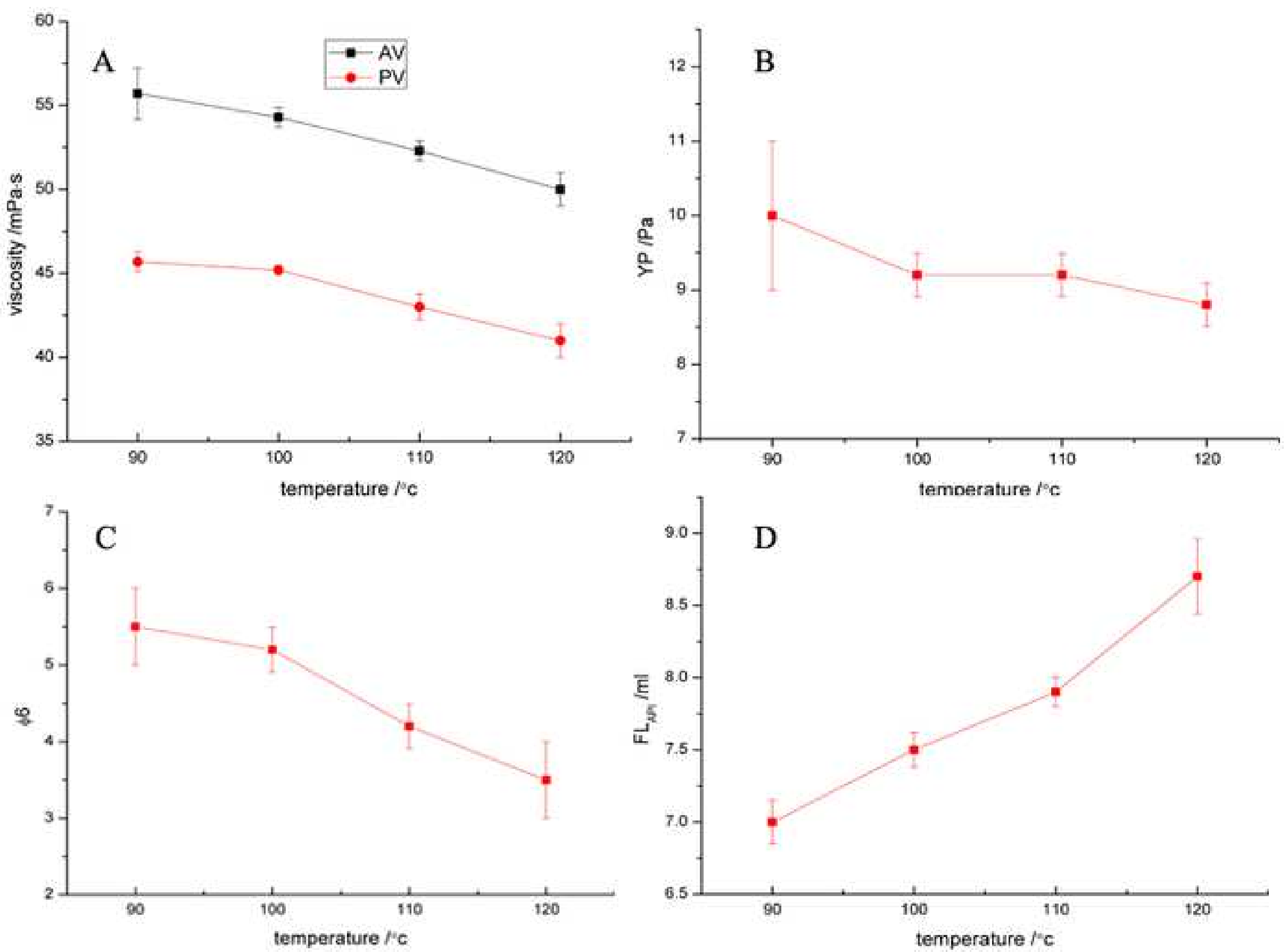
Click here to access/download Supplementary Material (Text) Supplementary information.docx 


\section{Please read the important information on page 4 before you begin}

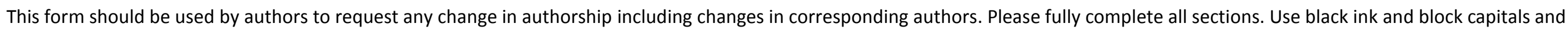
provide each author's full name with the given name first followed by the family name.

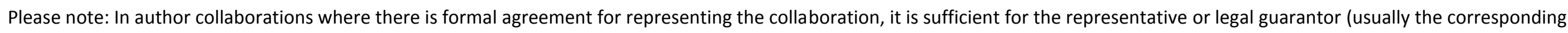
author) to complete and sign the Authorship Change Form on behalf of all authors.

\section{Section 1: Please provide the current title of manuscript}

(For journals: Please provide the manuscript ID, title and/or DOI if available.)

(For books: Please provide the title, ISBN and/or DOI if available.)

\begin{tabular}{|l|}
\hline Manuscript ID no. in case of unpublished manuscript: \\
\hline DOI in case of published manuscript: \\
\hline ISBN (for books): \\
\hline
\end{tabular}

Title: $\quad$ Experimental Investigation into A Novel Supersaturated Saline Drilling Fluid Available in Anhydrite Formation: A Case study of Missan Oilfield, Iraq

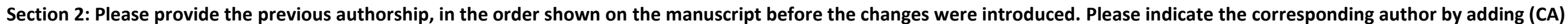
behind the name.

\begin{tabular}{|c|c|c|c|}
\hline & First name(s) & Family name & ORCID or SCOPUS id, if available \\
\hline $1^{\text {st }}$ author & Lin & $\mathrm{Xu}$ & \\
\hline $2^{\text {nd }}$ author & Jie & $\mathrm{Xu}$ & \\
\hline $3^{\text {rd }}$ author & Fuchang & You & \\
\hline $4^{\text {th }}$ author & Mingbiao & $\mathrm{Xu}$ & \\
\hline $5^{\text {th }}$ author & Jun & Gao & \\
\hline $6^{\text {th }}$ author & Meilan & Huang & \\
\hline $7^{\text {th }}$ author & & & \\
\hline
\end{tabular}

Please use an additional sheet if there are more than 7 authors.

SPRINGER NATURE springer Nature is one of the world's leading global research, educational and professional publishers, created in May 2015 through the combination of Nature Publishing Group, Palgrave Macmillan, Macmillan Education and Springer Science+Business Media. 


\section{Change of authorship request form (pre-acceptance)}

Section 3: Please provide a justification for change. Please use this section to explain your reasons for changing the authorship of your manuscript, e.g. what necessitated the change in authorship? Please refer to the (journal) policy pages for more information about authorship. Please explain why omitted authors were not originally included and/or why authors were removed on the submitted manuscript.

Complementary work was mainly carried out by Xin Huang and, thus, Huang was listed as the second author for her contribution, which have been agreed by co-authors.

Section 4: Proposed new authorship. Please provide your new authorship list in the order you would like it to appear on the manuscript. Please indicate the corresponding author by adding (CA) behind the name. If the corresponding author has changed, please indicate the reason under section 3.

\begin{tabular}{|l|c|c|}
\hline & First name(s) & $\begin{array}{l}\text { Family name (this name will appear in full on the final publication and will be searchable in various abstract and indexing } \\
\text { databases) }\end{array}$ \\
\hline $1^{\text {st }}$ author & Lin & Xu \\
\hline $2^{\text {nd }}$ author & Xin & Huang \\
\hline $3^{\text {rd }}$ author & Fuchang & You \\
\hline $4^{\text {th }}$ author & Jie & Xu \\
\hline $5^{\text {th }}$ author & Mingbiao & Xu \\
\hline $6^{\text {th }}$ author & Jun & Gao \\
\hline $7^{\text {th }}$ author & Meilan & Huang \\
\hline
\end{tabular}

Please use an additional sheet if there are more than 7 authors. 


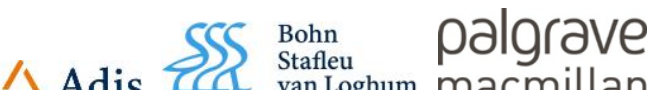
$\triangle$ Adis $2 \pi$ vantoghum macmillan

\section{Springer Change of authorship request form (pre-acceptance)}

Section 5: Author contribution, Acknowledgement and Disclosures. Please use this section to provide a new disclosure statement and, if appropriate, acknowledge any contributors who have been removed as authors and ensure you state what contribution any new authors made (if applicable per the journal or book (series) policy). Please ensure these are updated in your manuscript - after approval of the change(s) - as our production department will not transfer the information in this form to your manuscript.

\section{New acknowledgements:}

New Disclosures (financial and non-financial interests, funding):

New Author Contributions statement (if applicable per the journal policy):

Xin Huang, as a new author, has completed most complementary experiments linked with reviewers' advices.

State 'Not applicable' if there are no new authors. 
Change of authorship request form (pre-acceptance)

Section 6: Declaration of agreement. All authors, unchanged, new and removed must sign this declaration.

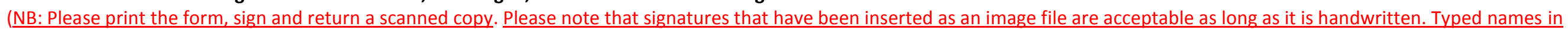
the signature box are unacceptable.) * Please delete as appropriate. Delete all of the bold if you were on the original authorship list and are remaining as an author.

\begin{tabular}{|c|c|c|c|c|c|c|}
\hline & First name & Family name & & Signature & Affiliated institute & Date \\
\hline $\begin{array}{l}1^{\text {st }} \\
\text { author }\end{array}$ & Lin & Xu & $\begin{array}{l}\text { I agree to the proposed new authorship } \\
\text { shown in section } 4 \text { /and the } \\
\text { addition/removal* of my name to the } \\
\text { authorship list. }\end{array}$ & & Zhejiang Ocean University & July 172020 \\
\hline $\begin{array}{l}2^{\text {nd }} \\
\text { author }\end{array}$ & Xin & Huang & $\begin{array}{l}\text { I agree to the proposed new authorship } \\
\text { shown in section } 4 \text { /and the } \\
\text { addition/removal* of my name to the } \\
\text { authorship list. }\end{array}$ & & $\begin{array}{l}\text { China University of Petroleum } \\
\text { (Beijing) }\end{array}$ & July 172020 \\
\hline $\begin{array}{l}3^{\text {rd }} \\
\text { author }\end{array}$ & Fuchang & You & $\begin{array}{l}\text { I agree to the proposed new authorship } \\
\text { shown in section } 4 \text { /and the } \\
\text { addition/removal* of my name to the } \\
\text { authorship list. }\end{array}$ & ung You & $\begin{array}{c}\text { Jiahua Technology Co., Ltd } \\
\text { Yangtze University }\end{array}$ & July 172020 \\
\hline $\begin{array}{l}4^{\text {th }} \\
\text { authors }\end{array}$ & Jie & Xu & $\begin{array}{l}\text { I agree to the proposed new authorship } \\
\text { shown in section } 4 \text { /and the } \\
\text { addition/removal*of my name to the } \\
\text { authorship list. }\end{array}$ & & $\begin{array}{l}\text { Chinese Academy of Geological } \\
\text { Sciences }\end{array}$ & July 172020 \\
\hline $\begin{array}{l}5^{\text {th }} \\
\text { author }\end{array}$ & Mingbiao & Xu & $\begin{array}{l}\text { I agree to the proposed new authorship } \\
\text { shown in section } 4 \text { /and the } \\
\text { addition/removal*of my name to the } \\
\text { authorship list. }\end{array}$ & mo Xn & Yangtze University & July 172020 \\
\hline $\begin{array}{l}6^{\text {th }} \\
\text { author }\end{array}$ & Jun & Gao & $\begin{array}{l}\text { I agree to the proposed new authorship } \\
\text { shown in section } 4 \text { /and the } \\
\text { addition/removal*of my name to the } \\
\text { authorship list. }\end{array}$ & $\ln ^{\infty}$ & $\begin{array}{l}\text { CNOOC (China) Co., Ltd, } \\
\text { Shanghai Branch }\end{array}$ & July 172020 \\
\hline $\begin{array}{l}7^{\text {th }} \\
\text { author }\end{array}$ & Meilan & Huang & $\begin{array}{l}\text { I agree to the proposed new authorship } \\
\text { shown in section } 4 \text { /and the } \\
\text { addition/removal*of my name to the } \\
\text { authorship list. }\end{array}$ & Me & Queen's University Belfast & July 172020 \\
\hline
\end{tabular}

Please use an additional sheet if there are more than 7 authors.

SPRINGER NATURE springer Nature is one of the world's leading global research, educational and professional publishers, created in May 2015 through the combination of Nature Publishing Group, Palgrave Macmillan, Macmillan Education and Springer Science+Business Media. 


\section{Important information. Please read.}

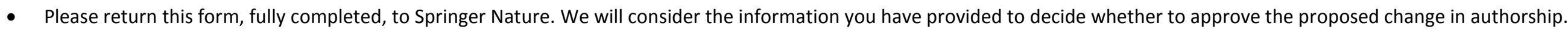
We may choose to contact your institution for more information or undertake a further investigation, if appropriate, before making a final decision.

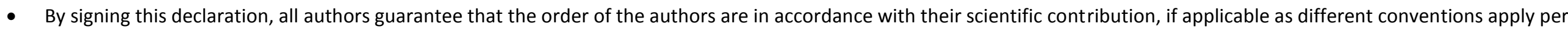
discipline, and that only authors have been added who made a meaningful contribution to the work.

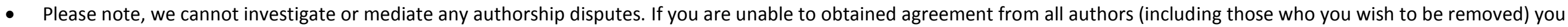
must refer the matter to your institution(s) for investigation. Please inform us if you need to do this.

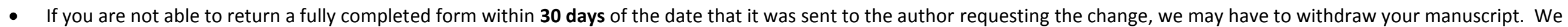
cannot publish manuscripts where authorship has not been agreed by all authors (including those who have been removed).

- Incomplete forms will be rejected. 